\title{
Human Genetics \& Embryology
}

\section{The Odyssey of Encode}

\section{Ana Paula de Souza Pardo*}

Department of Morphology, School of Dentistry of Piracicaba, University of Campinas, Brazil

Eleven years ago the Human Genome Project was finished and celebrated. After all, it was bringing the hope of cure for serious diseases, such as cancer, and surely new knowledge for scientists. However, passed the genome decade, perhaps a sense of frustration is felt once the cure of cancer was not reached, few questions get answers and a billion of new questions emerged from this "Pandora Box" named Human Genome. But what is left of this odyssey? As in any good story, good lessons.

The first lesson the scientists ever knew, the human genome is not only a sequence of nucleotide randomly organized but part of a microenvironment where DNA, RNA and proteins work in a complex and sophisticated pathway. The second lesson had also just been learned with the project of Human Genome: complex issues require efforts together to be solved. The third lesson was a conclusion from the first and second lessons: a new project integrating efforts of scientists of worldwide will be needed to answer the open questions which led to the introduction of the ENCODE project (Encyclopedia Of DNA Elements).

The ENCODE project started off at 2003 and represents the efforts of more than 440 scientists that aspired to map and describe the location of the most important pieces of DNA sequences and DNA chemical modifications which work in concert to build an organism, using a data set derived from 147 cell types. And the set of elements include, at least, the description of methylation pattern of all $\mathrm{CpG}$ dinucleotides in genome, regions of open chromatin, the map of modified histones, the targets of transcription factors, the targets of non-coding RNAs and regions hipersensitive to DNAse. Now, put all in a functionally way! Not simple apparently and not simple in practice.

And what was impressive about ENCODE project was its capacity to build assemble much of the puzzle that was left incomplete by Human Genome Project only nine years after. The consortium showed that $80 \%$ of the genome is biochemically functional once regarded as "junk" is filled with innumerous genes promoters, enhancers and targets for micro and small RNAs transcript which are not translated. ENCODE also describes the amazing highway where the intersection of two different mRNAs on each strand of DNA reconstructs the scenario of the large viaducts.

Furthermore, there was still the difficulty in managing a large consortium. As pointed by Dr. Ewan Birney, the coordinator of ENCODE, the consortium "involves people who might be competing with one another in another context", and yet according to Dr. Birney, the success was achieved due to the clarity and codes of conducts established among participants, who had to learn to work for the common good, learning to overcome many times their own egos and self interests. The forth lesson!

Officially, the results of ENCODE project were announced through 30 coordinated articles recently in Nature, Genome Research and Genome Biology. Has the project come to an end? The answer is "no", and probably it will not have one. Perhaps, when the goal is to unveil the intriguing life engineering, large projects are still small. And to expect the solutions for great problems as cancer in a short time may just bring frustrations. The solutions came step by step according to our efforts which must be in cooperative projects. Finally, that is the final lesson.
*Corresponding author: Ana Paula de Souza Pardo, Department of Morphology, School of Dentistry of Piracicaba, University of Campinas, Brazil, E-mail: anapaulapardo@fop.unicamp.br

Received November 27, 2012; Accepted November 28, 2012; Published November 30, 2012

Citation: de Souza Pardo AP (2012) The Odyssey of Encode. Human Genet Embryol 1:e107. doi:10.4172/2161-0436.1000e107

Copyright: ( 2012 de Souza Pardo AP. This is an open-access article distributed under the terms of the Creative Commons Attribution License, which permits unrestricted use, distribution, and reproduction in any medium, provided the original author and source are credited. 